\title{
Dijital Finansal Okuryazarlık ve Bireylerin Finansal Teknoloji Kullanma Konusundaki Tutumları
}

\author{
DOI: 10.26466/opus.584628 \\ * \\ Sibel Fettahoğlu* - Duygu Kıldıze** \\ * Doç. Dr, Kocaeli Üniversitesi, IİBF, Umuttepe- İzmit / Kocaeli \\ ORCID: 0000-0003-0783-9776 \\ ** Kocaeli Üniversitesi, SBE, İşl. Böl., Muhasebe ve Finansman YLS Prog./ Umuttepe-İzmit/Kocaeli \\ ORCID: $\underline{0000-0002-8819-9573}$
}

E-Posta: stopdemir@kocaeli.edu.tr

E-Posta: duygukldz@gmail.com

Öz

Finansal hizmetlerin daha hızl ve kolay bir şekilde kullanılması için finans ve teknolojinin bir araya gelmesiyle oluşan yeni akım "FinTech" olarak tanımlanmaktadır. Bu çalışmada tesadüfi örnekleme yöntemi ile seçilmiş 102 kişinin öncelikle dijital finans alanındaki okuryazarlıkları ölçülmüştür. Ayn zamanda FinTech'in beraberinde getirdiği dijital finansal ürün ve hizmetlere karşı katıllmcıların tutumları ve kullanım oranları incelenmiştir. Anket sorularıyla katılımcıların finansal teknolojileri kullanma tutumu üzerinde etkili olduğu düşünülen yedi faktör belirlenmiştir: (1) Algılanan risk, (2) Operasyonel risk, (3) Güvenlik riski, (4) Hukuki risk, (5) Aracısız İşlem Yapma, (6) Algılanan Fayda ve (7) Ekonomik faydadır. Çalışmada elde edilen bulgularda; katılımcıların dijital finansal ürün ve hizmetlerin büyük bir kısmı hakkında bilgi sahibi olduğu ancak kullanımı için daha fazla bilgi gerektiren uygulama ve araçlar için ise eğitim ve bilgilendirmenin gerekli olduğu ortaya çıkmaktadır. Bunun yanında aracısız işlem yapma kolaylı̆̆ının, katılımcıların dijital finansal ürün ve hizmetlere karşı tutum ve davranışları üzerinde oldukça etkili olduğu görülmektedir.Öncelikli olan konu, gençlere dijital teknolojileri, uygulamaları ve ürünleri öğrenmeleri için eğitim vermektir. Yenilik ve marka yaratmak için girişimcilere teşvikler verilmelidir. Dijital dönüşüm ve dijital finansal yenilikler gerçekleştirilemezse gelişmekte olan ülkeler için rekabet daha zor olacaktır.

Anahtar Kelimeler: Finansal teknoloji, Dijital finansal okuryazarlık, Elektronik finansal ürünler, Tutum. 


\title{
Digital Financial Literacy and Attitudes of Individuals about Using Financial Technologies
}

\begin{abstract}
'Fintech" is defined as a new stream that is comprised by the combination of finance and technology in order to use of financial services easier and faster. In this study, 102 people were selected by random sampling method and primarily their literacy in finance was measured. At the same time the attitudes and usage rates of the participants about the digital financial products and services have been examined. Seven factors were determined as effected to individuals' attitudes about using financial technologies: (1) Perceived risk, (2) Operational risk, (3) Security risk, (4)Legal risk, (5) Seamless transaction, (6) Perceived benefit and (7) Economic benefits. The results of the study showed that participants have information about a large part of digital financial products and services but more education and information are necessary for using applications and tools that require more information for their use. Besides, it was seen that the seamless transaction factor was quite effective on participants' attitudes and behaviors towards using digital financial products and services. Primary matter is to give education to young people to learn digital technologies, applications and products. Incentives must be given to startups for create innovations and brands. If digital transformation and digital financial innovations cannot be realized, competition will be more hard for developing countries.
\end{abstract}

Keywords: Financial technology, Digital financial literacy, Electronic financial products, Attitude 


\section{Giriş}

Finansal hizmetlerin daha hızlı, kolay ve kaliteli bir şekilde kullanıcılara sunulması için finans ve teknolojinin bir araya gelmesinden oluşan yeni akım "FinTech" olarak tanımlanmaktadır(Fettahoğlu, 2017a, s.53). Finansal teknolojiler, maliyetleri azaltma, daha fazla şeffaflık sağlama, aracıları azaltma ve finansal bilgiye erişimi sağlama konusunda bireylere firsatlar sağlar(Zavokolina vd., 2016, s.1). Finansal teknoloji kullanıcıları, finansal teknolojiyi kullanmanın beklenen değerini, fayda ve maliyetlerini bilmek ister. Fayda- maliyet açısından bakılırsa kullanıc, finansal teknolojiye dayalı ürün ya da hizmetlerden sağlayacağı faydanın, katlanacağı maliyetten yüksek olmasını ister. Ancak bu durumda söz konusu ürün ya da hizmeti kullanmayı tercih edecektir. Bireylerin finansal teknolojileri kullanmalarını etkileyen pozitif ve negatif faktörler söz konusudur. Bu çalışmanın amacı, öncelikle bireylerin dijital finansal okuryazarlıkları konusunda bir fikir edinmek ve ikinci etapta finansal teknolojiye dayalı ürün ya da hizmetleri kullanma konusundaki tutumlarını belirleyebilmektir. Çalışma üç bölümden oluşmaktadır: Birinci bölümde finansal teknoloji kavramı, belli başli elektronik finansal ürün ve hizmetler ile bireylerin finansal teknoloji kullanımına ilişkin tutumları üzerinde durulmuştur. İkinci bölümde çalışmanın yöntemi, üçüncü bölümde araştırmanın bulguları ve sonuç kısmında ise çalışmanın genel bir değerlendirmesi yapılmıştır.

\section{Finansal Teknoloji Kavramı}

Finansal teknolojiye ilişkin olarak literatürde yapılan çeşitli tanımlamalar söz konusudur: Arner ve diğerleri(2015, s.3)'ne göre finansal teknoloji, teknolojiye olanak veren finansal çözümlerdir. Lee ve $\operatorname{Kim}(2015$, s.58)'e göre finansal teknoloji, geleneksel sistemi etkileyebilecek yeni finansal yazılımları(software) geliştirme ve uygulamayı içeren teknik bir süreçtir. $\operatorname{Ryu}(2017$, s.543)' ya göre finansal teknoloji, bilişim teknolojilerinin anahtar konumda olduğu finansal olmayan şirketlerce oluşturulan yenilik yaratıcı finansal hizmet ve ürünlerdir. Finansal teknoloji sayesinde kullanıcılar, çeşitli mobil hizmetler üzerinden ödeme yapma, para transfer etme, kredi başvurusu yapma, sigorta satın alma, portföy yönetimi ve yatırım yapmayı gerçekleştirebilmektedir. 
Finansal hizmetler soyuttur ve bilişim ve iletişim teknolojilerindeki gelişmeler bunları sağlamanın maliyetini ciddi ölçüde azaltmaktadır. Bilişim teknolojisi, finansal hizmetlerde rekabeti artırarak yabancı ülkelerde bulunan rakiplerin yerel pazarlara girmelerini kolaylaştırır ve fiyat biçimlenme sürecini daha şeffaf hale getirir(Sato ve Hawkins, 2001, s.1-12). Finansal teknoloji, yatırımcıların aracı kuruluşlarla olan ilişkilerinde de değişimlere yol açmıştır.

\section{Elektronik Finansal ürün ve Hizmetler}

Çok çeşit ve sayıda uygulama ve finansal yenilikler olmakla birlikte bu başlık altında özellikle anket formunda katılımclara yöneltilen elektronik finansal ürün ve hizmetler tanıtılmaya çalışılmaktadır. Kripto para birimleri, internet ve e-ticaretin gelişmesiyle birlikte ortaya çıkmış, merkezi bir otoriteye bağlı olmayan ve kriptografik sistemler ile güvenliği sağlanan dünya çapında kullanılan para birimleridir(Aslantaş Ateş, 2016, s.349). Bitcoin, Lindencoin vbg birçok sanal para bulunmaktadır. Bunlardan en yaygin olarak bilinen sanal para Bitcoin'dir.

Elektronik para, internette kullanılmak üzere geliştirilmiş dijital bir paradır. Her elektronik paranın bir seri numarası vardır. İnternet üzerinden harcama yapıldığında belli seri numaralı elektronik paralar alışveriş yapanın bilgisayarından silinerek alışveriş yapılan bilgisayara geçirilir(Şeker,2011, s.55-73). BDDK'dan yetki belgesi almış elektronik para kuruluşları elektronik para çıkarabilir.

Akıllı kart(smartcard), kart temelli bir ödeme aracıdır. Akıllı kart ile işlem hızı artmaktadır. Üzerinde bulunan çip sayesinde elektronik parada dahil olmak üzere her türlü bilgi yüklemesi yapılabilmektedir.

Kağıt çeklerde bulunan bilgiler elektronik çeklerde de bulunmaktadır. 1 Ocak 2017 yılından itibaren kare kodlu çekler uygulamaya geçilmiştir. Bu uygulama ile çek ödeme geçmişine kolaylıkla ulaşılabilir. Ayrıca sahtecilik ve dolandırıcılığın büyük ölçüde önüne geçilebilmektedir.

EFT, gelişen iletişim teknolojisi ve bilgisayarların daha etkin kullanımı ile hesapta bulunan fonun, başka bir hesaba kaydi para olarak hızlı bir şekilde aktarılmasıdır. Kullanıcısının kimlik, kredi kartı, adres bilgilerini barındıran, bu bilgilerin otomatik olarak kullanılmasını sağlayan bir sistemdir. EFT sistemi ile kayıt dışılığın önlenmesi ve sağlıklı bilgi alışverişi 
sağlanmaktadır. Elektronik fatura uygulamalarında faturalar internet üzerinden oluşturulur ve fatura ödemesi yine elektronik ortamdan yapılabilmektedir.

Kitle fonlama(crowdfunding), girişimcinin iş fikrini finanse etmek için kitle fonlama platformları üzerinden yatırımcılarla aracısız ve internet üzerinden doğrudan buluşmasını sağlayan bir mekanizmadır. Kitle fonlama, melek yatırım ve girişim sermayesine benzer gibi görünse de bu iki finansman yöntemine alternatif olarak ortaya çıkmaktadır(Fettahoğlu ve Khusayan, 2017b, s.503).

Dijital cüzdan kullanıcısına, otopark ödemesi, mobil alışveriş, ev anahtarı, ajanda gibi daha örneği çoğaltılabilecek birçok hizmeti vermektedir. Turkcell Cüzdan, PayPass, BKM Express birer dijital cüzdan örneği$\operatorname{dir}(Z e n g i n$ ve Güngördü, 2013, s.137).

Dijital bankacilık, şubeye ya da telefon bankacılığına başvurmadan bankacılık işlemlerini elektronik kanallar üzerinden gerçekleştirilmesine olanak tanıyan sistemdir. Bu sayede hem zamandan hem de bankacilık masraflarından tasarruf edilmesini sağlar. Cepteteb, Enpara, Nuvo, Dijital Deniz, İGaranti, Akbank Direkt dijital bankacılık örneklerindendir.

Elektronik sigorta ile, işletmeden işletmeye(B2B) e-ticaret modelinde olduğu gibi sigorta şirketleri acenteleri ile internet üzerinden doğrudan sigortacılık yapabileceği gibi; işletmeden tüketiciye(B2C) e-ticaret modelinde olduğu gibi müşterilerin online sigorta teklifi ya da poliçesi oluşturmasına olanak tanıyabilir.

Elektronik ortamda kredi derecelendirme notunun belirlenmesini sağlayan platformlar üzerinden hesaplanan kredi notuna göre kredi olanakları, kredi tekliflerini karşılaştırma yapılabilmektedir.

İnternet ortamında yapılan alışverişlerde kart bilgilerinin kötü amaçlı kişilerce ele geçirilmesi riski endişe vericidir. Bu doğrultuda, internet üzerinden yapılan alışverişlerde kullanılan bir kredi kartı olan sanal kredi kartı geliştirilmiştir. Sanal kredi kart ile bireyler alışveriş öncesinde sistemde çevrimiçi olarak kart bilgilerini oluşturup, kart limiti belirleyip sonra bu limiti sıfırlayıp kapatabilir. Böylece, kötü amaçlı kimselerin kullanımından doğacak riskleri azaltmak daha mümkün hale gelmiştir(Bilir ve Çay, 2015, s.27-29, Zengin ve Güngördü 2013, s.136). 
Teknolojiye en çok yatırım yapan sektörlerin başında gelen, verimliliği artırmak ve işlem maliyetini en aza indirgemek isteyen bankacılık sektörü, müşterilerini internet bankacılığı ve mobil bankacılığa yönlendirmektedir. Türkiye'de geçmişi 1997 yılına dayanan internet bankacılığını ilk olarak Türkiye İş Bankası ve Garanti Bankası müşterilerinin hizmetine sunmuştur.

Karekod teknolojisi NFC teknolojisi temel alınarak oluşturulmuş bir uygulamadır. NFC teknolojisine uygun bilgisayarlar ve cep telefonları ile kredi kartı, kurumsal kartlar, ulaşım kartı ya da banka kartları gibi kartların bütünleştirilerek, POS cihazı ya da ürün ile buluşturması sonucu sistem devreye girer.

Bankalar, müşterilerine birebir kişiselleştirilmiş ürün ve hizmetler sunmak adına akıllı sanal asistan(enlightened virtua lassistan-EVA) yazılımlarını tasarlamaktadır. Sesli komut verme, ödeme zamanı konusunda kullanıcıyı bilgilendirme, kullanıcının kişisel tercihleri ile finansal seçenekler arasında en uygun olanını eşleştirme gibi birçok açıdan kullanıcısına yardımcı olmayı hedefleyen yapay zeka yazılımlarıdır(Fettahoğlu, 2017a, s.41).

\section{Bireylerin Finansal Teknoloji Kullanımına İlişkin Tutumları}

Finansal teknoloji kullanımına ilişkin olumlu düşünceler algılanan faydayı artırırken aksine olumsuz düşünceler algılanan risk ile sonuçlanacaktır. Literatür taraması yapıldığında finansal teknoloji kullanımına ilişkin bireylerin risk ve fayda algısı üzerinde etkili olan faktörleri araştıran çeşitli çalışmalar yapıldığı görülmektedir. Bunlardan bazıları şunlardır: Kim ve diğerleri(2008, s.546) çalışmalarında elektronik ticarette güveni etkileyen fayda ve risk faktörlerini araştırdılar. Lee (2009, s.131) çalışmasında internet bankacılığ 1 kullanımına ilişkin algılanan fayda ve risk faktörlerini ele almıştır. Risk faktörleri olarak, finansal risk, güvenlik, performans, sosyal ve zaman risklerini ölçümlemeye çalışmıştır. Liu ve diğerleri(2012, s.3) çalışmalarında bireylerin mobil ödeme konusundaki risk-fayda analizini yapmaya çalıştılar. Risk faktörü olarak finansal risk, güvenlik riski ve psikolojik riski ele aldılar. Abramova ve Böhme(2016, s.5) Bitcoin üzerine yapmış oldukları çalışmalarında finansal kayıplar, hukuki, operasyonel 
ve uyarlama risklerini incelediler. Finansal teknoloji kullanımından beklenen ekonomik fayda öncelikle, maliyetlerin azalması ve elde edilen finansal kazançtır. Bazı finansal teknoloji uygulamaları(mobil havale, P2P gibi) kullanıcılara geleneksel finansal hizmet sağlayıcılarından daha düşük maliyet sunabilirler(Mackenzie, 2015, s.50). P2P, kitle fonlama..vbg finansal teknoloji uygulamaları genellikle hizmetlerini online ya da mobil platformlar üzerinden kullanıcılarına sunarak fon sağlayanlara yüksek getiri, fon kullananlara düşük faiz avantajı sağlar. Finansal teknolojiler gelişmekte olan bir alan olduğu için finansal teknoloji kullanıcıları için çeşitli risk faktörleri söz konusu olabilir. Finansal risk, finansal teknoloji kullanımından kaynaklanabilecek finansal kayıpları ifade etmektedir. Finansal teknoloji kullanımından kaynaklanabilecek finansal kayıplar, finansal işlem sistemindeki aksaklıklardan, dolandırıcllık, ahlaki tehlike ve ilk kullanımın gerektireceği ek işlem ücretlerinden kaynaklanabilir. Finansal teknoloji kullanıcılarının bazıları riske girmeyi seven, teknoloji kullanımı ve yeniliklerle barışık bireyler olabileceği gibi, bazı kullanıcılar şüpheci, riske girmeyi sevmeyen, yenilikleri benimsemesi zaman alan tutum sergileyen kişiler olabilir. Diğer sektörlerden farklı olarak finans sektörüne has bazı özellikler(sistemsel yapıya olan güven, finansal işlem taraflarının birbirine olan güveni ...vbg) nedeniyle yeniliklerin benimsenmesi biraz daha zordur ve zaman almaktadır(Zavokolina vd., 2016, s.1-19).

\section{Araştırmanın Yöntemi}

Bireylerin dijital finansal okuryazarlık düzeylerini ve finansal teknoloji kullanma konusundaki tutumlarını belirlemek üzere İstanbul'da ikamet eden, tesadüfü örnekleme yöntemine göre seçilmiş, anket formunu eksiksiz bir şekilde dolduran 102 kişinin anketi değerlendirmeye alınmıştır. Analiz yorumları ve sonuçları, söz konusu örneklem için geçerli olup çalışmanın kısıtını oluşturmaktadır. Analiz yaparken önce katılımcıların dijital finansal okuryazarlık durumları incelenecek ardından ikinci kısımda ise katılımcıların finansal teknolojiye dayalı ürün ve hizmetleri kullanma tutumları üzerinde etkili olduğu düşünülen faktörler ile ilişkisi belirlenmeye çalışılacaktır. Anket sorularını hazırlarken Kim ve diğerleri(2008), Lee(2009), Okazaki ve $\operatorname{Mendez(2013),~Fettahoğlu(2015),~Abromova~ve~}$ Böhme(2016) ve Ryu(2017)'nin çalışmalarında yer alan anket sorularından 
yararlanılmıştır. Anket sorularıyla katılımcıların finansal teknolojileri kullanma tutumu üzerinde etkili olduğu düşünülen yedi faktör belirlenmiştir: (1) Algilanan risk, (2) Operasyonel Risk, (3) Güvenlik Riski, (4)Hukuki Risk, (5)Aracısız işlem yapma, (6) Algılanan fayda ve (7) Ekonomik faydadır. Analizi yaparken SPSS paket programı kullanılmıştır. Ankette yer alan ifadelerden faktörleri belirleyebilmek için faktör analizi yapılmıştır. Söz konusu faktörlerle kullanıcıların finansal teknolojileri kullanma tutumu arasındaki ilişkiyi belirleyebilmek için ise regresyon analizi kullanılmıştır.

\section{Araştırmanın Bulguları}

Ankete katılan 102 katılımcıya ilişkin olarak Tablo 1'de tanımlayıcı istatistikler yer almaktadır:

Tablo 1. Katılımcılara İlişkin Tanımlayıcı Bilgiler

\begin{tabular}{|c|c|c|}
\hline Değişken & Gözlem Sayısı & $\%$ \\
\hline \multicolumn{3}{|l|}{ Cinsiyet } \\
\hline Kadın & 51 & $\% 50$ \\
\hline Erkek & 51 & $\% 50$ \\
\hline \multicolumn{3}{|l|}{ Medeni Durum } \\
\hline Evli & 46 & $\% 45,1$ \\
\hline Bekar & 56 & $\% 54,9$ \\
\hline \multicolumn{3}{|l|}{ Eğitim Düzeyi } \\
\hline Okuryazar & 0 & $\% 0$ \\
\hline İlköğretim & 3 & $\% 2$ \\
\hline Lise & 16 & $\% 16$ \\
\hline Üniversite & 79 & $\% 78$ \\
\hline Yüksek Lisans-Doktora & 4 & $\% 4$ \\
\hline \multicolumn{3}{|l|}{ Yaş } \\
\hline $18-25$ & 20 & $\% 20$ \\
\hline $26-33$ & 22 & $\% 22$ \\
\hline $34-43$ & 38 & $\% 37$ \\
\hline $44-51$ & 18 & $\% 18$ \\
\hline $52+$ & 4 & $\% 3$ \\
\hline \multicolumn{3}{|l|}{ Gelir Düzeyi } \\
\hline 1000 TL den az & 8 & $\% 7$ \\
\hline $1001-2000 \mathrm{TL}$ & 13 & $\% 13$ \\
\hline 2001-3000 TL & 28 & $\% 28$ \\
\hline $3001-4000 \mathrm{TL}$ & 27 & $\% 27$ \\
\hline $4001-5000 \mathrm{TL}$ & 4 & $\% 3$ \\
\hline 5000 TL den fazla & 22 & $\% 22$ \\
\hline
\end{tabular}


Tablo 1'e göre anketi yanıtlayanların \%50'si kadın, \%50 si erkektir. Katılımciların \%55'i bekar, \%78'i üniversite mezunudur. 44 yaş altında olan katılımcların \%79 pay ile toplam katılımcılar içinde genç ve orta yaş düzeyinde yoğunlaştıkları görülmektedir. Katılımcıların \%55'inin geliri 2001-4000 TL arasindadir.

Kullanıcıların dijital finansal okuryazarlık düzeylerini belirlemek için daha önce duymuş oldukları finansal teknolojiye dayalı ürün ve hizmetleri işaretlemeleri istenmiştir. Tablo 2'de finansal teknolojiye dayalı ürün ve hizmetlerin bilinirlilik yüzdeleri görülmektedir.

Tablo 2. Finansal Teknolojiye Dayalı Ürün ve Hizmetlerin Bilinirlilik Yüzdeleri

\begin{tabular}{lll}
\hline $\begin{array}{l}\text { Finansal Teknolojiye Dayalı } \\
\text { Ürün ya da Hizmet }\end{array}$ & Adet & $\%$ \\
\hline Sanal para(Bitcoin, Lindencoin...vbg) & 88 & $\% 86$ \\
\hline Elektronik para(Elektronik para kuruluşlarından) & 49 & $\% 48$ \\
\hline Smart kart(Akıllı kart) & 52 & $\% 51$ \\
\hline Elektronik çek & 25 & $\% 25$ \\
\hline EFT(Elektronik fon transferi) & 94 & $\% 92$ \\
\hline Elektronik fatura & 84 & $\% 82$ \\
\hline Kitle fonlama(crowdfon, fongogo...vbg) & 9 & $\% 9$ \\
\hline Dijital cüzdan & 49 & $\% 48$ \\
\hline Dijital bankacılık(enpara.com, cepteteb....vbg) & 90 & $\% 88$ \\
\hline Elektronik sigorta(sigortam.net......vbg) & 58 & $\% 57$ \\
\hline $\begin{array}{l}\text { Elektronik ortamda kredi karşılaştırma } \\
\text { (hangikredi.com,hesapkurdu...vbg) }\end{array}$ & 60 & $\% 59$ \\
\hline Kredi derecelendirme hizmeti(findeks, kredico....vbg) & 69 & $\% 68$ \\
\hline Sanal kredi kartı & 78 & $\% 77$ \\
\hline İnternet bankacılığı & 102 & $\% 100$ \\
\hline Mobil bankacılık & 98 & $\% 96$ \\
\hline Kare kod uygulaması & 74 & $\% 73$ \\
\hline $\begin{array}{l}\text { Akıllı sanal asistan(Garanti Bankası UGİ, } \\
\text { İş Bankası Maxi.....vbg) }\end{array}$ & 54 & $\% 53$ \\
\hline
\end{tabular}

Tablo 2 incelendiğinde katılımcılar ilk üç sırada en çok "İnternet bankac1lığı", "Mobil bankacılık" ve "EFT" yi bilirken en az oranda "Kitle fonlama" bilinmektedir. Kullanıcılara daha önceki soruda kendilerine sorulan finansal teknolojiye dayalı ürün ve hizmetlerden hangilerini kullandıkları(uyguladıkları) sorulmuştur. Alınan cevaplara göre katılımcılar, ilk üç sırada en çok yine "İnternet bankacılığı", "Mobil bankacılık" ve "EFT" 
yi kullanırken, en az oranda "Kitle fonlama" yı uygulamışlar ve hiçbiri "Elektronik çek" kullanmamıştır.

Tablo 3. Finansal Teknolojiye Dayalı Ürün ve Hizmetlerin Kullanma(Uygulama) Yüzdeleri

\begin{tabular}{|c|c|c|}
\hline $\begin{array}{l}\text { Finansal Teknolojiye Dayalı } \\
\text { Ürün ya da Hizmet }\end{array}$ & Adet & $\%$ \\
\hline Sanal para(Bitcoin, Lindencoin...vbg) & 16 & $\% 16$ \\
\hline Elektronik para(Elektronik para kuruluşlarından) & 9 & $\% 9$ \\
\hline Smart kart(Akıllı kart) & 13 & $\% 13$ \\
\hline Elektronik çek & 0 & $\% 0$ \\
\hline EFT(Elektronik fon transferi) & 82 & $\% 80$ \\
\hline Elektronik fatura & 46 & $\% 45$ \\
\hline Kitle fonlama(crowdfon, fongogo...vbg) & 1 & $\% 1$ \\
\hline Dijital cüzdan & 18 & $\% 18$ \\
\hline Dijital bankacılık(enpara.com, cepteteb....vbg) & 43 & $\% 42$ \\
\hline Elektronik sigorta(sigortam.net.....vvg) & 27 & $\% 27$ \\
\hline $\begin{array}{l}\text { Elektronik ortamda kredi karşılaştırma } \\
\text { (hangikredi.com,hesapkurdu..vbg) }\end{array}$ & 41 & $\% 40$ \\
\hline Kredi derecelendirme hizmeti(findeks, kredico....vbg) & 34 & $\% 33$ \\
\hline Sanal kredi kartı & 49 & $\% 48$ \\
\hline İnternet bankacılığ1 & 96 & $\% 94$ \\
\hline Mobil bankacılık & 92 & $\% 90$ \\
\hline Kare kod uygulaması & 38 & $\% 37$ \\
\hline $\begin{array}{l}\text { Akıllı sanal asistan(Garanti Bankası UGİ, } \\
\text { İş Bankası Maxi.....vbg) }\end{array}$ & 13 & $\% 13$ \\
\hline
\end{tabular}

Tablo 2 ve Tablo 3 birlikte değerlendirildiğinde katılımcıların dijital finansal ürün ve hizmetlerin büyük bir kısmı hakkında bilgiye, farkındalığa sahip olduğu görülmektedir. Ancak söz konusu dijital finansal ürün ve hizmetleri kullanma(uygulama) açısından daha çok internet ve mobil bankacılığı yoğun olarak kullandıkları biraz daha fazla bilgi birikimi gerektiren ürün ve hizmetleri ise kullanmaktan kaçındıkları söylenebilir.

Katılımcıların demografik özelliklerine göre finansal teknolojiye dayalı ürün ve hizmetleri kullanımlarında bir farklılık olup olmadığını incelemek için ANOVA analizi yapılmıştır. Cinsiyete göre katılımcıların aracısız işlem yapma faktörü açısından finansal teknolojiye dayalı ürün ve hizmetleri kullanma farklılı̆̆ı Tablo 4 ve Tablo 5'te, algılanan fayda faktörü aç1sindan farklılık ise Tablo 6 ve Tablo 7 'de görülmektedir: 
Tablo 4. Cinsiyete Göre Katılımcıların Aracısız İşlem Yapma Faktörü Açısından Finansal Teknolojiye Dayalı Ürün ve Hizmetleri Kullanma Farklılı̆̆ı

\begin{tabular}{lllll}
\hline & Kareler Toplamı & Ortalama Kareler Toplamı & F & Anlamlılık \\
\hline Gruplar Arası & 1,922 & 1,922 & 6,955 &, 01 \\
Gruplar İçi & 27,630 & & & \\
Toplam & $\mathbf{2 9 , 5 5 1}$ & $\mathbf{2 7 6}$ & &
\end{tabular}

Tablo 5. Cinsiyete Göre Katılımcıların Aracısız İşlem Yapma Faktörü Açısından Finansal Teknolojiye Dayalı Ürün ve Hizmetleri Kullanma Farklılı̆̆ı Tanımlayıcı İstatistikleri

\begin{tabular}{llll}
\hline & Gözlem Sayısı & Ortalama & Standart Sapma \\
\hline Kadın & 51 & 2,18 &, 55 \\
Erkek & 51 & 1,90 &, 49 \\
Toplam & $\mathbf{1 0 2}$ & $\mathbf{2 , 0 4}$ & $\mathbf{, 5 4}$ \\
\hline
\end{tabular}

Tablo 4 ve Tablo 5 birlikte değerlendirildiğinde kadın katılımcıların erkek katılımcılara göre finansal teknolojiye dayalı ürün ve hizmetleri kullanırken aracısız işlem yapma faktörüne ortalamanın üzerinde önem verdiği söylenebilir. Aracısız işlem yapma, finansal işlem yaparken geleneksel finansal kurumlara olan bağımlılığı ortadan kaldırması açısından büyük önem taşır. Ayrıca maliyet açısından değerlendirildiğinde dijital ortamda işlem gerçekleştirmek kullanıcılara işlem maliyetleri açısından tasarruf olanağı sağlamaktadır.

Tablo 6. Cinsiyete Göre Katılımcıların Algılanan Fayda Faktörü Açısından Finansal Teknolojiye Dayalı Ürün ve Hizmetleri Kullanma Farklılı̆̆ı

\begin{tabular}{|c|c|c|c|c|}
\hline & $\begin{array}{l}\text { Kareler Top- } \\
\text { lamı }\end{array}$ & Ortalama Kareler Toplamı & $\mathbf{F}$ & Anlamlılık \\
\hline Gruplar Arası & 2,109 & 2,109 & 7,505 & 00 \\
\hline Gruplar İçi & 30,208 & ,281 & & \\
\hline Toplam & 28,099 & & & \\
\hline
\end{tabular}

Tablo 7. Cinsiyete Göre Katılımcıların Algılanan Fayda Faktörü Açısından Finansal $\underline{\text { Teknolojiye Dayalı Ürün ve Hizmetleri Kullanma Farklılığı Tanımlayıcı İstatistikleri }}$

\begin{tabular}{llll}
\hline & Gözlem Sayısi & Ortalama & Standart Sapma \\
\hline Kadın & 51 & 1,89 &, 55 \\
Erkek & 51 & 1,60 &, 49 \\
Toplam & $\mathbf{1 0 2}$ & $\mathbf{1 , 7 5}$ & $\mathbf{, 5 4}$ \\
\hline
\end{tabular}


Tablo 6 ve Tablo 7 birlikte değerlendirildiğinde kadın katılımcıların erkek katılımclara göre finansal teknolojiye dayalı ürün ve hizmetlerin kullanımında algıladıkları faydanın ortalamanın üzerinde olduğu söylenebilir. Mobil ve internet bankacılığında olduğu gibi kullanıcılar zaman ve yer sorunu olmadan istedikleri yer ve zamanda işlemlerini gerçekleştirebilmektedirler. Kadın katılımcların bu bağlamda finansal teknolojiye dayalı ürün ve hizmetleri kullanırken erkek katılımcılara kıyasla ortalamanın üzerinde bir oranda daha kaliteli ve daha hızlı işlem yaptıkları şeklinde bir algılanan faydaya sahip oldukları söylenebilir.

Yaş grubuna göre "26-33 yaş" grubunda olan katılımcıların güvenlik riski faktörü açısından finansal teknolojiye dayalı ürün ve hizmetleri kullanma farklılığı Tablo 8 ve Tablo 9'da görülmektedir:

Tablo 8. "26-33 Yaş” Grubu Katılımcıların Güvenlik Riski Faktörü Açısından Finansal Teknolojiye Dayalı Ürün ve Hizmetleri Kullanma Farklılı̆̆ı

\begin{tabular}{|c|c|c|c|c|}
\hline & $\begin{array}{l}\text { Kareler Top- } \\
\text { lamı }\end{array}$ & Ortalama Kareler Toplamı & $\mathbf{F}$ & Anlamlılık \\
\hline Gruplar Arası & 5,582 & 5,582 & 6,988 & ,01 \\
\hline Gruplar İçi & 85,453 & 799 & & \\
\hline Toplam & 79,872 & & & \\
\hline
\end{tabular}

Tablo 9. "26-33 Yaş" Grubu Katılımcıların Güvenlik Riski Faktörü Açısından Finansal Teknolojiye Dayalı Ürün ve Hizmetleri Kullanma Farklılı̆̆ Tanımlayıcı İstatistikleri

\begin{tabular}{llll}
\hline & Gözlem Sayısı & Ortalama & Standart Sapma \\
\hline $\begin{array}{l}\text { 26-33 Yaş } \\
\begin{array}{l}\text { Arası Olanlar } \\
\text { 26-33 Yaş Arası }\end{array}\end{array}$ & 22 & 3 &, 21 \\
$\begin{array}{l}\text { Olmayanlar } \\
\text { Toplam }\end{array}$ & 80 & 2,43 &, 09 \\
\hline
\end{tabular}

Tablo 8 ve Tablo 9 birlikte değerlendirildiğinde “26-33 yaş" grubunda yer alan genç katılımcıların diğer yaş grubunda olan katılımcılara göre finansal teknolojiye dayalı ürün ve hizmetleri kullanırken güvenlik riski faktörüne ortalamanın üzerinde önem verdiği söylenebilir. Güvenlik riski, bilgisayar korsanları ve dolandırıcılar nedeniyle ortaya çıkabilecek olası kayıpları ifade eder. Ayrıca finansal teknoloji kullanımı beraberinde kişisel veriler ve gizlilik gibi konuları ön plana çıkarmaktadır. Bu durum fintech 
kullanımı konusunda algılanan riskin artmasına neden olmaktadır. Bu algıyı ortadan kaldırmak için Avrupa' da kişisel verilerin toplanması, depolanması, kullanımı ve aktarımı 1995 yılında düzenlenen "Avrupa Kişisel Veri Koruma Direktifleri" ile düzenlenmiştir. Türkiye' de 24.03.2016 tarihli Resmi Gazetede yayınlanan 6698 sayılı "Kişisel Verilerin Koruması Kanunu" yürürlüğe girmiştir.

Gelir düzeyine göre "2001-3000 TL" gelir grubunda olan katılımcıların operasyonel risk faktörü açısından finansal teknolojiye dayalı ürün ve hizmetleri kullanma farklılığı Tablo 10 ve Tablo 11'de görülmektedir:

Tablo 10. “2001-3000 TL” Gelir Grubunda Olan Katılımcıların Operasyonel Risk Faktörü Açısından Finansal Teknolojiye Dayalı Ürün ve Hizmetleri Kullanma Farklılı̆̆ı

\begin{tabular}{lllll}
\hline & $\begin{array}{l}\text { Kareler } \\
\text { Toplamı }\end{array}$ & $\begin{array}{l}\text { Ortalama Ka- } \\
\text { reler Toplamı }\end{array}$ & F & Anlamlılık \\
\hline $\begin{array}{l}\text { Gruplar Arası } \\
\text { Gruplar İçi }\end{array}$ & 3,021 & 3,021 & 4,026 &, 04 \\
Toplam & 75,021 &, 750 & & \\
\hline
\end{tabular}

Tablo 11. “2001-3000 TL” Gelir Grubunda Olan Kattlimcilarnn Operasyonel Risk Faktörü Açısından Finansal Teknolojiye Dayalı Ürün ve Hizmetleri Kullanma Farklılığı Tanımlayıcı İstatistikleri

\begin{tabular}{llll}
\hline & Gözlem Sayıs & Ortalama & Standart Sapma \\
\hline $\begin{array}{l}\text { “2001-3000 TL" Gelir } \\
\text { Grubunda Olanlar }\end{array}$ & 28 & 3,19 &, 80 \\
$\begin{array}{l}\text { "2001-3000 TL" Gelir } \\
\begin{array}{l}\text { Grubunda Olmayanlar } \\
\text { Toplam }\end{array}\end{array}$ & 74 & 2,81 &, 88 \\
\hline
\end{tabular}

Tablo 10 ve Tablo 11 birlikte değerlendirildiğinde "2001-3000 TL" gelir düzeyinde yer alan katılımcıların diğer gelir düzeyinde olan katılımcılara göre finansal teknolojiye dayalı ürün ve hizmetleri kullanırken operasyonel risk faktörüne ortalamanın üzerinde önem verdiği söylenebilir. Operasyonel risk, yetersiz ve başarısız iç süreçlerden, çalışanlar ve sistemden kaynaklanan potansiyel zararı ifade eder. Finansal teknoloji uygulamalarına yönelik finansal sistem ve işlemlerin risk olasılığı yüksekse kullanıc1lar fintech kullanmayı tercih etmeyecektir. Operasyonel becerilerin olmaması, sistemlerin hatalı çalışması, yetersiz iç süreçler kullanıcılar üzerinde güvensizlik ve memnuniyetsizlik yaratacaktır. Dolayısıyla alt gelir düzeyinin biraz üzerinde yer alan bu kullanıcı grubu açısından kısıtlı gelirinin 
kullanımının yapılacağı fintech uygulama ve ürünleri açısından operasyonel risk faktörü önemli hale gelmektedir.

Çalışmanın ikinci kısımda, katılımcıların finansal teknolojiye dayalı ürün ve hizmetleri kullanma tutumları üzerinde etkili olduğu düşünülen faktörler ile ilişkisi belirlenmeye çalışılacaktır. Finansal teknolojileri kullanma tutumu üzerinde etkili olduğu düşünülen faktörleri belirlemeye yönelik olarak 5'li likert ölçeğine göre oluşturulan ifadeler için güvenilirlik analizi yapılmış olup Cronbach alfa değeri \%77,4 olarak bulunmuştur. Bu değer \%70'in üzerinde bir değer olduğu için anket ölçeği güvenilir olarak kabul edilebilir. Faktör analizine uygunluğunun sınanması için Barlett testi ve Kaiser-Mayer-Olkin(KMO) ölçütüne bakılmıştır. Barlett testi verilerin birbiriyle ilişkili olup olmadığını göstermektedir. Barlett testi değeri 915,247 Sig.0,00 olarak hesaplanmıştır. KMO testi ise örneklem büyüklügünün faktör analizi için uygunluğunu inceler. KMO değeri 0,73 olarak hesaplanmıştır. KMO değerinin 0,60 dan büyük olması örneklem büyüklüğünün yeterli olduğunu ifade eder. Dolayısıyla veriler faktör analizi için uygundur. Yapılan faktör analizi ile ortaya konan 7 faktör ve faktörleri belirlemeye yönelik katılımcılara yöneltilen ifadeler Tablo 12' deki gibidir:

Tablo 12. Faktör Analizi Sonuçları

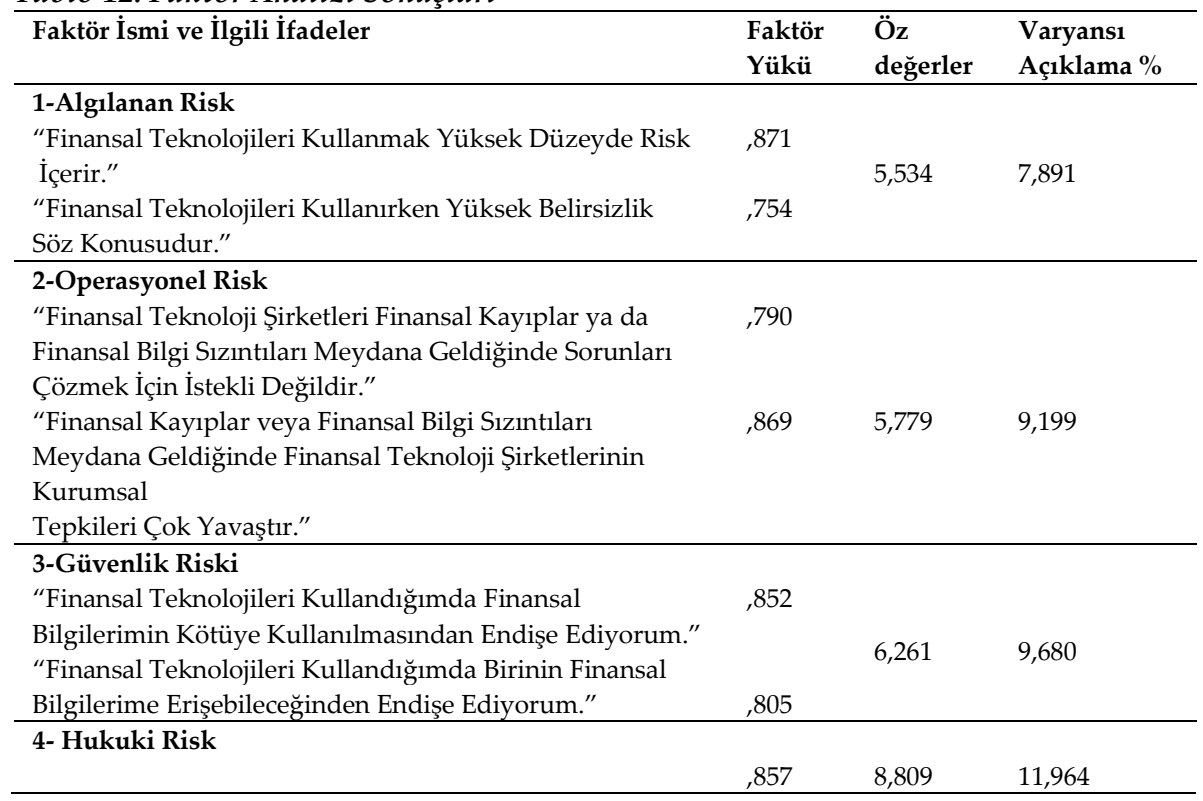




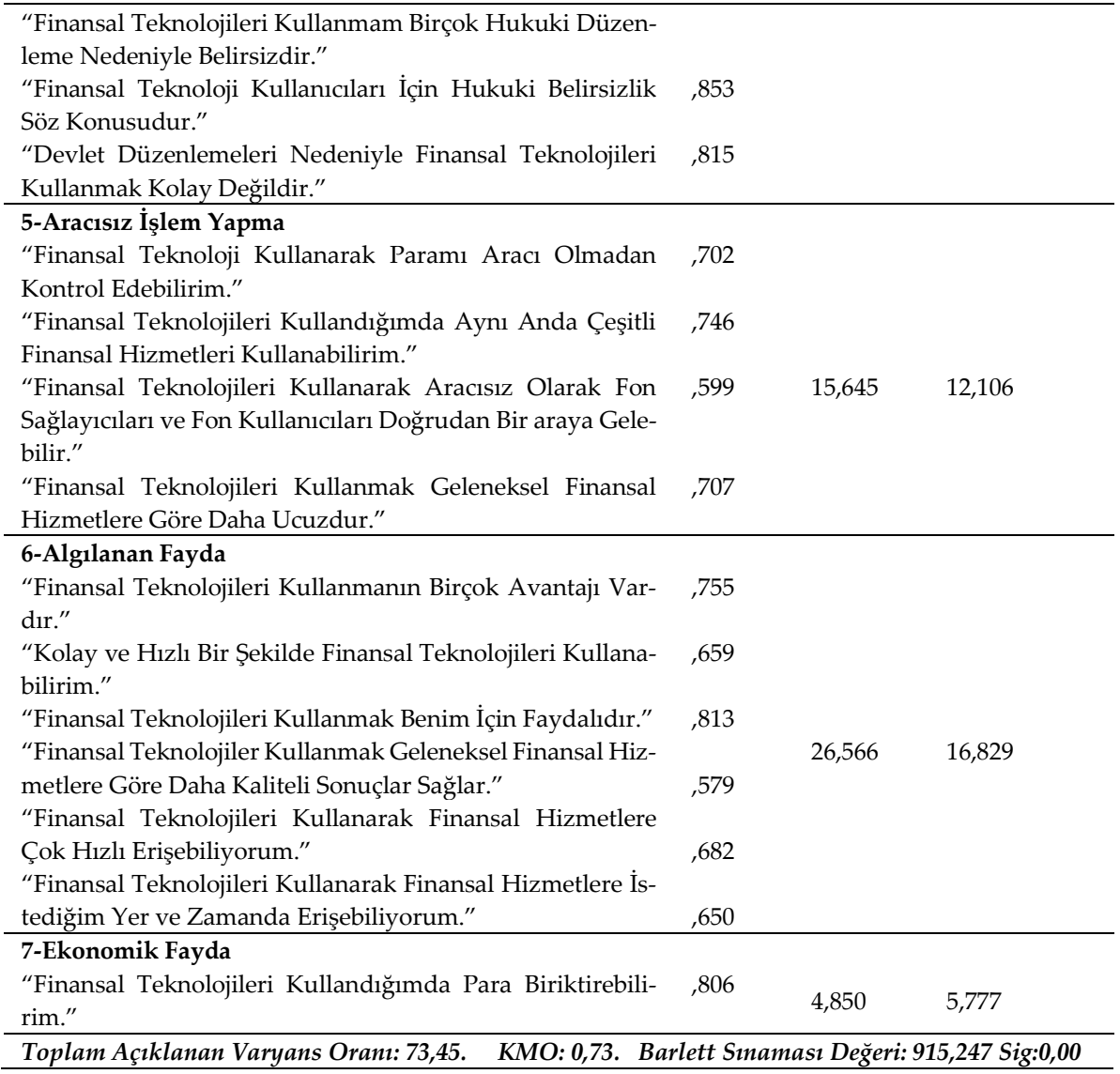

Faktör ortalamaları incelendiğinde 1. sırada 3,27 ortalamayla algılanan risk faktörü bulunmaktadır. Özellikle risk algısı, kullanıcıların tutumunu belirlerken dikkate aldıkları etkili bir faktördür. 2. sırada 3,24 ortalamayla hukuki risk faktörü yer almıştır. Hukuki risk, finansal teknolojilere ilişkin yasal düzenlemelerin olmaması ya da yasal durumunun net belirtilmemiş olmasından kaynaklanmaktadır. Hukuki düzenlemelerin yetersizliği ya da hiç olmaması finansal teknoloji kullanıcıları açısından güvensizlik ve endişeye yol açabilir. 3. sırada 2,91 ortalamayla operasyonel risk, 4 . sırada ise 2,84 ortalamayla ekonomik fayda faktörü yer almaktadır. 5. sırada 2,55 ortalamayla güvenlik riski, 6 . sırada 2,04 ortalamayla aracısız işlem yapma 
ve son olarak 7. sırada 1,75 ortalamayla algılanan fayda faktörü yer almıştir.

Bireylerin finansal teknoloji kullanma konusundaki tutumları ile söz konusu 7 faktör arasındaki ilişkiyi belirlemek için regresyon analizi uygulanmıştır. Regresyon analizinde bağımlı değişken bireylerin finansal teknoloji kullanma konusundaki tutumu iken bağımsız değişkenler faktör analizi ile ifade edilen ilgili 7 faktördür. Tablo 13 te bağımlı değişkeni oluşturmak üzere katılımcllara yöneltilen ifadeler yer almaktadır:

Tablo 13. Bağımlı Değişkeni Ölçmek İçin Katılımcılara Yöneltilen İfadeler

\begin{tabular}{l}
\hline "Finansal Teknolojileri Kullanmayı Tercih Ederim." \\
\hline "Finansal Teknolojileri Kullanmaya Devam Etmeyi Planlıyorum." \\
\hline “Gelecek Zamanda Finansal Teknolojileri Kullanacağım." \\
\hline
\end{tabular}

Regresyon analizinde kademeli(stepwise) regresyon analizi seçeneği uygulanarak çok sayıda bağımsız değişken içinden bağımlı değişkeni en iyi açıklayan maksimum sayıda değişken belirlenmeye çalışılmıştır. VIF değerlerine bakılarak bağımsız değişkenler arasında yüksek korelasyon olmamasına dikkat edilmiştir. VIF değeri büyüdükçe bağımsız değişkenler arasında ciddi bir çoklu doğrusal bağlantı söz konusudur. VIF değerinin 10'dan küçük olması beklenir. Tablo 14 ve Tablo 15 te regresyon analizi model özeti ile bağımlı ve bağımsız değişkenler için regresyon katsayıları görülmektedir:

Tablo 14. Finansal Teknolojileri Kullanma Tutumu İle Bağımsız Değişkenler İçin Regresyon Modeli Özeti

\begin{tabular}{lllll}
\hline & R & R2 & Düzeltilmiş R2 & Anlamlılık \\
\hline Model Özeti &, 750 &, 563 &, 554 &, 00 \\
\hline
\end{tabular}

Bağımlı Değişken: Finansal Teknolojileri Kullanma Tutumu

Tablo 15. Finansal Teknolojileri Kullanma Tutumu İle Bağımsız Değişkenler İçin Regresyon Katsayısı

\begin{tabular}{llllll}
\hline & Katsayılar & $\begin{array}{l}\text { Standardize } \\
\text { Edilmiş } \\
\text { Katsayılar }\end{array}$ & $\mathrm{t}$ & Anlamlılık & VIF \\
\hline Sabit &,- 211 & &,- 977 &, 33 & \\
Algilanan Fayda &, 801 &, 557 & 6,986 &, 00 & 1,441 \\
Aracisız İşlem Yapma &, 408 &, 281 & 3,519 &, 00 & 1,441 \\
\hline
\end{tabular}

Bă̆ıml Değişken: Finansal Teknoloji Kullanma Tutumu 
Tablo 14 ve Tablo 15 incelendiğinde $0,00(<0,05)$ anlamlılık düzeyinde modelin bir bütün olarak geçerli olduğunu ve modelde yer alan "algılanan fayda" ve "aracısız işlem yapma" bağımsız değişkenlerinin finansal teknolojileri kullanma tutumundaki değişmelerin \%55,4'ünü açıkladığı görülmektedir. Algilanan fayda ve aracısız işlem yapma faktörleri, katılımcıların finansal teknolojiye dayalı ürün ve hizmetleri kullanmaları üzerinde pozitif bir etkiye sahiptir. Buradan katılımcların finansal teknolojiye dayalı ürün ve hizmetleri kullanma tutumları üzerinde riske dayalı faktörlerden çok fayda ve aracısız işlem yapmanın yarattığı kolaylığın daha etkili olduğu söylenebilir. Katılımcıların finansal riskin oluşabileceği fintech uygulama ve ürünlerini kullanma yüzdelerinin düşük olduğu hatırlanırsa bu iki faktörün ön plana çıkması analiz sonuçlarının birbirleriyle örtüştüğünün bir göstergesidir.

\section{Sonuç}

İstanbul'da ikamet eden, tesadüfü örnekleme yöntemine göre seçilmiş, anket formunu eksiksiz bir şekilde dolduran 102 kişinin anket formları değerlendirildiğinde aşağıdaki sonuçlara ulaşılmaktadır:

- Katılımciların dijital finansal ürün ve hizmetlerin büyük bir kısmı hakkında bilgiye, farkındalığa sahip olduğu görülmektedir. Biraz daha fazla bilgi birikimi gerektiren ürün ve hizmetleri kullanmaktan kaçındıkları görülmüştür.

- Kadın katılımcıların, aracısız işlem yapma faktörü ile finansal teknolojiye dayalı ürün ve hizmetlerin kullanımında erkek katılımcılara göre algıladıkları faydanın ortalamanın üzerinde olduğu belirlenmiştir.

- "26-33 yaş" grubunda yer alan genç katılımcıların diğer yaş grubunda olan katılımclara göre finansal teknolojiye dayalı ürün ve hizmetleri kullanırken güvenlik riskinin ön plana çıktığı belirlenmiştir.

- "2001-3000 TL" gelir düzeyi ile alt gelir düzeyinin biraz üzerinde yer alan bu kullanıcı grubu açısından kısıtlı gelirinin kullanımının yapılacağı fintech uygulama ve ürünleri açısından operasyonel risk faktörünün önemli olduğu görülmüştür. 
- Algılanan fayda ve aracısız işlem yapma faktörlerinin, katılımcıların finansal teknolojiye dayalı ürün ve hizmetleri kullanmaları üzerinde pozitif bir etkiye sahip olduğu belirlenmiştir.

- Örneklem açısından katılımcıların finansal teknolojiye dayalı ürün ve hizmetleri kullanma tutumları üzerinde riske dayalı faktörlerden çok fayda ve aracısız işlem yapmanın yarattığı kolaylığın daha etkili olduğu belirlenmiştir.

Örneklem kitle, dijital finansal okuryazarlık açısından değerlendirildiğinde gerek görsel gerekse yazılı medya araçları ile farkındalık oluşturulduğu için temel düzeydeki finansal teknolojilere vakıf oldukları görülmektedir. Kullanımı için daha fazla bilgi gerektiren uygulama ve araçlar için ise eğitim ve bilgilendirmenin gerekli olduğu ortaya çıkmaktadır. Bu bağlamda Türkiye Ekonomi Bankası(TEB) dijital finansal okuryazarlığın sağlanmasına katkıda bulunmak için ücretsiz olarak Blockchain, kodlama ve yeni nesil finansal yöntemler hakkında üniversite öğrencileri başta olmak üzere isteyen herkese açık eğitimler sunmaktadır.

2008 küresel finansal krizinin yaşanması ile finansal kurumlara özellikle bankalara olan güvenin azalması, internet ve internete dayalı teknolojilerin hızla gelişmesi finansal pazarlarda aracısız bir şekilde finansal işlem yapma isteğini ve olanaklarını ortaya koymuştur. Dolayısıyla başta finansal kurumlar olmak üzere tüm finans sektöründe müşterilerin, kullanıcıların istek ve beklentilerini en iyi şekilde karşılayacak, hızlı, kolay, düşük maliyetli ve kişiselleştirilmiş ürünleri gerçekleştirecek finansal yenilikler oluşturulmaya çalışılmaktadır. Deloitte(2017)'in Türkiye Fintech Ekosistemi raporuna göre Türkiye'de Fintech yatırımlarının miktarı 2016 yılında bir önceki yıla göre \%175 büyüyerek 29 Milyon Dolara ulaşmıştır. Gereken dijital dönüşümü gerçekleştiremeyen ülkeler önümüzdeki süreçte yarışın gerisinde kalacaklardır. Dünyada Endüstri 4.0 ve yapay zekanın odak noktası olduğu bir ortamda gençlerin dijital finansal teknoloji ve uygulamaları bilen, işlem gerçekleştirebilen ve bu konuda kendini geliştirebilecekleri eğitimlerin verilmesi öncelikli bir konudur. Aynı zamanda finansal yeniliklerin ve teknolojilerin oluşturulabilmesi için startup olarak isimlendirilen girişimcilere gereken desteklerin sağlanarak yeniliklerin yaratılabilmesi ve markalaşmasına ortam yaratılmalıdır. Bireylerin finansal teknolojileri kullanma isteklerini belirleyen öncelikli faktörlerin aracısız işlem yapma ve fayda algısının olması ilerleyen dönemlerde 
yaratılacak yeniliklerde nelerin ön plana alınması konusunda da bir fikir vermektedir.

\title{
EXTENDED ABSTRACT
}

\section{Digital Financial Literacy and Attitudes of Individuals about Using Financial Technologies}

\author{
Sibel Fettahoglu - Duygu Kıldıze \\ *
}

Kocaeli University

\begin{abstract}
"Fintech" is defined as a new stream that is comprised by the combination of finance and technology in order to use of financial services easier and faster (Fettahoglu, 2017a). Financial technologies give opportunities to individuals about reducing costs, allowing transparency, cutting middlemen and make financial information accessible (Zavokolina vd., 2016). There are some positive and negative factors that influence individuals' using of financial technologies.

The aim of the study was firstly to determined digital financial literacy of individuals and at the second step to determine individuals' attitudes about using electronic financial products or services. 102 participants who lived in Istanbul and selected by random sampling method, filled the survey completely and their survey results were evaluated. Analysis results and discussions were limited by the sample and this was the constraint of the study. Survey questions were prepared with the help of some studies: (Kim et all. 2008; Lee, 2009; Okazaki ve Mendez, 2013; Fettahoglu, 2015; Abromova ve Böhme, 2016; Ryu, 2017). Seven factors were determined as effected to individuals' attitudes about using financial technologies: (1) Perceived risk, (2) Operational risk, (3) Security risk, (4) Legal risk, (5) Seamless transaction, (6) Perceived benefit and (7) Economic benefit.
\end{abstract}


The results of the study showed that participants have information about a large part of digital financial products and services but more education and information are necessary for using applications and tools that require more information for their use. Results showed that:

According to female participants' average of benefits about seamless transaction for using financial technologies and services were higher than male participants' average.

According to "26-33 years old" young participants gave more importance on security risk for using financial technologies and services than the other groups of age. Security risk is defined as potential losses from hackers and frauds. Policymakers must give more importance about protect personal data and privacy topics because of increases about using financial technologies.

Participants who have "2001-3000 TL" income as just little higher than low income level gave more importance on operational risk for using financial technologies and services. Operational risk is defined as potential losses from failed internal process, systems and employees. If risk level is high about applications and financial transactions, users will not prefer to use FinTechs. Lack of operational skills will cause dissatisfaction and distrust.

Five point Likert-type scale was used for to determine factors which had an effect on attitudes about using financial technologies. Reliability analysis was assessed using Cronbah's alfa. Cronbah's alfa was found $77,4 \%$. This value was upper than $70 \%$ so the survey scale could be accepted valid. Barlett Test value was found 915,247 Sig.0,00. Kaiser-MayerOlkin(KMO) value was found 0,73 . If $\mathrm{KMO}$ value is upper than 0,60 , this shows that sample size is enough.

Average of factors can be showed in the following: Perceived risk was in the first rank with 3,27 average point. Legal risk was in the second rank with 3,24 average point. Legal risk exists if regulations about financial technologies don't constituted or these regulations are insufficient. Legal risk causes distrust and anxiety. Operational risk average was 2,91 and economic benefits factor average was 2,84 . In the fifth rank security risk(2,55 average); in the sixth rank seamless transaction factor(2,04 average) and in the last rank perceived benefit factor with average 1,75 were found. 
Regression analysis was made to determine relations between seven factors and attitudes about financial technology usage. Regression results expressed that model was valid in $0,00(<0,05)$ significance level; perceived benefit and seamless transaction variables explained 55,4\% per cent the changes for attitude about financial technology usage.

Perceived benefit and seamless transaction factors were determined as factors which had positive effectiveness on participants for using financial technologies and services.

It was seen that the seamless transaction factor was quite effective on participants' attitudes and behaviours towards using digital financial products and services. Seamless transaction factor is important factor that eliminates traditional financial institutions through finance process. At the same time users take advantages about cost reduction when they prefer digital platforms for making financial transactions.

Primary matter is to give education to young people to learn digital technologies, applications and products. Incentives must be given to startups for create innovations and brands. If digital transformation and digital financial innovations cannot be realized, competition will be hard for developing countries.

\section{Kaynakça / References}

Abromova, S. ve Böhme, R. (2016). Perceived benefits and risk as multidimensional determinants of bitcoin use: A quantitative exploratory study, International Conference on Information System, Dublin, 11-14 December. 1-20.

Arner, D.W., Barberis, J.N. ve Buckley, R.P. (2015). The evolution of fintech: A new post crisis paradigm?. SSRN Papers, 15.12.2018 tarihinde http://ssrn.com/abstract=2676553 adresinden erişilmiştir.

Ateş, A. B. (2016). Kripto para birimleri, bitcoin ve muhasebesi, Sosyal Bilimler Enstitüsü Dergisi, 7(1), 349-366.

Bilir, H. ve Çay, Ş.(2016). Elektronik para ve finansal piyasalar arasındaki ilişki, İktisadi ve İdari Bilimler Fakültesi Dergisi, 9(2), 21-31.

Deloitte(2017). Türkiye fintech ekosistemi raporu, (Rapor No:Nisan 2017), Nisan, 1-12. 
Fettahoğlu, S. (2015). Hane halkının finans eğitimi ve finansal okuryazarlık düzeyleri üzerine Kocaeli'nde bir araştırma, Muhasebe ve Finansman Dergisi, 67, 101-115.

Fettahoğlu, S. (2017a). E-finans. İzmit: Umuttepe Yayınları.

Fettahoğlu, S. ve Khusayan, S. (2017b). Yeni finansman olanağı: Kitle fonlama, Uşak Üniversitesi Sosyal Bilimler Dergisi, 10(4), 497-521.

Kim, D.J., Ferrin, D.L. ve Rao, H.R. (2008). A trust based consumer decision-making model in electronic commerce: The role of trust, perceived risk and their antecedents, Decision Support Systems, 44(2), 544-564.

Lee, M.C. (2009). Factors influencing the adoption of internet banking: An integration of TAM and TPB with perceived risk and perceived benefits. Electronic Commerce Research and Applications, 8(3), 130141.

Lee, T.H. ve Kim, H.W. (2015). An Exploratory study on fintech industry in Korea: Crowdfunding case. 2nd International Conference on Innovative Engineering Technologies, Bangkok, 25.12.2018 tarihinde iieng.org/images/proceedings_pdf/7333E0815045.pdf adresinden erişilmiştir.

Liu, Y., Yang, Y. ve Li, H. (2012). A unified risk-benefit analysis framework for investigating mobile payment adoption. International Conference on Mobile Business.Paper 20.

Mackenzie, A. (2015). The fintech revolution. London Business School Review, 26(3), 50-53.

Okazaki, S. ve Mendez, F. (2013). Exploring convenience in mobile commerce: Moderating effects of gender, Computers in Human Behavior, $29,1234-1242$.

Ryu, H.S. (2017). What makes users willing or hesitant to use fintech?: The moderating effect of user type. Industrial Management $\mathcal{E}$ Data Systems, 118(3), 541-569.

Sato, S. ve Hawkins, J. (2001). Electronic finance: An overview of the issues, BIS Papers, 7, 1-12.

Şeker, M. (2011). Elektronik ödeme sistemleri. İstanbul Ticaret Üniversitesi Sosyal Bilimler Dergisi, 20, 53-75. 
Zavolokina, L., Dolata, M ve Schwabe, G. (2016). FinTech-what's in a name?, Proceedings in International Conference on Information Systems, Dublin, 11-14 December, 1-19.

Zengin, B. ve Güngördü A. (2013). Elektronik ödeme sistemlerinin olası etkileri üzerine bir inceleme, İktisadi ve İdari Bilimler Fakültesi Dergisi, 15(3), 129-150.

\section{Kaynakça Bilgisi / Citation Information}

Fettahoğlu, S. ve Kıldıze, D. (2019). Dijital finansal okuryazarlık ve bireylerin finansal teknoloji kullanma konusundaki tutumları OPUSUluslararası Toplum Araştırmaları Dergisi, 12(18. UíK Özel Sayısı), 867-889. DOI: 10.26466/opus.584628 